\title{
衝撃熱負荷を受ける傾斜機能厚肉回転対称殻の応力と変形*
}

\author{
竹 園 茂 男*1, 垰 \\ 克 已*1 \\ 稲村栄次郎*2, 小澤 義 央*3
}

\section{Thermal Stress and Deformation in Moderately Thick Shells of Revolution of Functionally Graded Material under Thermal Impulsive Loading}

\author{
Shigeo TAKEZONO, Katsumi TAO*4, \\ Eijiroh INAMURA and Yoshihiro OZAWA \\ *4 Toyohashi University of Technology, Dept. of Mechanical Engineering, \\ Tempaku-cho, Toyohashi, Aichi, 441-8580 Japan
}

\begin{abstract}
This paper describes an analytical formulation and a numerical solution of the thermal stress and deformation for moderately thick shells of revolution made of functionally graded material (FGM) subjected to thermal impulsive loading. The material properties of the shell are continuously inhomogeneous along the shell thickness. The temperature distribution through the shell thickness is expressed with a curve of high order, and the equations of motion and the relations between the strains and displacements are derived from the Reissner-Naghdi shell theory. The fundamental equations derived are numerically solved using the finite difference method. As numerical examples, functionally graded cylindrical shells subjected to the following two kinds of thermal impulsive loads are treated; one is the thermal loads due to fluid and another is the loads due to heat generation in the shell body. In comparison with the results from the characteristic method, good agreement is obtained. And it is found that the temperature distributions, stress distributions and deformations with time are significantly varied depending on the compositional distribution profiles in FGM.
\end{abstract}

Key Words : Structural Analysis, Thermal Shock, Functionally Graded Material, Thermal Stress, Thick Shells, Elasticity, FDM

\section{1. 緒言}

傾斜機能材料は，過酷な熱環境において優れた機械 的強度を有する材料として近年開発が進められてい る.この新材料を機器部品に適用したときの静的な熱 忘力を解析した研究は多数報告されているが(1), 電磁 波，レーザ， $\gamma$ 線等により材料が短時間の内に急激な 加熱を受けるような動的問題に関しては, 平板や円筒, 中空球等の単純な形状を対象に, 特性曲線法を用いて 解析したものに限られている(2) (6). 著者らは, 既に傾 斜機能材料から成る一般軸対称薄肉殼が，流体加熱や 内部発熱により衝撃熱負荷を受ける場合の動的応答問 題の解法を示したが(7), 本研究では中程度の厚さ(殼 厚を $h$, 主曲率半径を $R$ とおくと, $1 / 20<h / R<1 / 5$ 程度)の傾斜機能回転対称殼の動的応答問題の解法を 取扱った，傾斜機能材料の組成分布は，殼厚方向に変 化する材料物性值を愿さ方向の関数で表し, 壳厚方向

* 原稿受付 1999 年 8 月 30 日.

*1 正員, 豊橋技術科学大学 (区 441-8580 豊橋市天伯町雲雀ヶ 丘 1-1).

*2 正員, 東京都立工業高等専門学校 (\$140-0011 東京都品川 区東大井 1-10-40).

*3 信越化学工業(株)（画915-8515 武生市北府 2-1-5)

E-mail : tao@mech.tut.ac.jp
に数值積分することによって，基礎式の諸係数に組込 まれる，著者らは，既報( ${ }^{(8)}$ で傾斜機能材料から成る殼 は高温流体加熱を受けると, 応答初期に殼厚方向に局 所的にこう配の急な温度分布を生じるため, 壳厚方向 の温度分布を任意の高次曲線で近似することが有効で あることを示した。本研究でもその解析手法を適用 し，与えられた初期条件と境界条件のもとで, 熱伝導 方程式を解く．そして高次曲線の次数を変えて解の収 束性を調心゙，温度分布を表す多項式の適切な次数を決 定する，得られた温度分布をもとに，回転対称殼の基 礎関係式から, 変位, 内力などを求める.壳の基礎関 係式には，款厚方向のせん断変形を考慮した Reissner -Naghdi の理論(9)(10) を用いた。導かれた基礎式の数 值解法には, 差分法を適用した。

数值解析例として, 殼厚方向に不均質性を有する傾 斜機能円筒殻に, 軸対称な衝撃熱負荷が作用する問題 を二例取り上げた。一つは，無限長の円筒殼内表面に 一様流体加熱を受ける場合で, 変位と応力の解を特性 曲線法による解 (3) と比較し, 本解法の妥当性を確認し た。もう一つは，両端単純支持の円筒殼に，子午線方 向に局所的な内部発熱による衝擊熱負荷が作用する問 題を取り上げた。 


\section{2. 基 礎 式}

図1亿示すように，殼の中央面上に子午線方向に $\xi$, 円周方向に $\theta$, 中央面加外向きに $\zeta$ 座標軸をと る。対称軸から中央面までの距離を $R$ とし，殼の中 央面の形を $R=R(s)$ で与えると, 中央面の点 $\mathrm{P} に お$ ける無次元曲率 $\omega_{\xi}\left(=a / R_{s}\right), \omega_{\theta}\left(=a / R_{\theta}\right)$ 押よび無次 元半径 $r(=R / a)$ の間には, 次の関係が成立する。た だし $s$ は子午線方向の長さであり， $a$ は代表長さであ る.

$$
\begin{aligned}
& \omega_{\xi}=-\left(\gamma^{\prime}+\gamma^{2}\right) / \omega_{\theta}, \quad \omega_{\theta}=\sqrt{1-\left(r^{\prime}\right)^{2}} / r \\
& \omega_{\theta}^{\prime}=\gamma\left(\omega_{\xi}-\omega_{\theta}\right), r^{\prime \prime} / r=-\omega_{\xi} \omega_{\theta} \\
& \gamma=r^{\prime} / r, \xi=s / a,(\quad)^{\prime}=d(\quad) / d \xi
\end{aligned}
$$

$2 \cdot 1$ 熱伝導方程式 材料特性值が殼厚方向のみ に変化する傾斜機能厚肉殼体内の熱伝導方程式は, $\xi$, $\theta, \zeta$ 座標を用いて次式で与えられる。

$$
\begin{gathered}
\frac{\partial T}{\partial t}-\frac{1}{a^{2} r L_{\xi} L_{\theta}}\left\{\chi \frac{\partial}{\partial \xi}\left(r \frac{L_{\theta}}{L_{\xi}} \frac{\partial T}{\partial \xi}\right)+\frac{\chi L_{\xi}}{r L_{\theta}} \frac{\partial^{2} T}{\partial \theta^{2}}\right. \\
\left.+\frac{1}{c \rho} \frac{\partial}{\partial \zeta}\left(a^{2} r L_{\xi} L_{\theta} \lambda \frac{\partial T}{\partial \zeta}\right)\right\}-\frac{\eta}{c \rho}=0
\end{gathered}
$$

ここに, $L_{\xi}=1+\zeta / R_{s}, L_{\theta}=1+\zeta / R_{\theta}, T$ : 任意の時刻 における殼体内の任意の点 $(\xi, \theta, \zeta, t)$ の温度, $\chi$ : 温 度伝導率 $[=\lambda /(c \rho)], c$ : 比熱, $\rho$ : 密度, $\lambda$ : 熱伝導 率, $\eta:$ 単位時間, 単位体積当たりの発熱量, $t:$ 時間 である。

また，殼の内外表面 $(\zeta=\mp h / 2)$ の温度境界条件は

$$
\left.\begin{array}{l}
{\left[\frac{\partial T}{\partial \zeta}\right]_{\zeta=-h / 2}=k_{\text {in }}\left(T_{\text {in }}-\Theta_{\text {in }}\right)} \\
{\left[\frac{\partial T}{\partial \zeta}\right]_{\zeta=h / 2}=-k_{\text {out }}\left(T_{\text {out }}-\Theta_{\text {out }}\right)}
\end{array}\right\} .
$$

ここに, $\Theta_{\mathrm{in}}, \Theta_{\mathrm{out}}$ : 款の内外の周囲温度, $k_{\mathrm{in}}, k_{\mathrm{out}}$ : 款 の内外表面の相対熱伝達率 $\left[K_{\text {in }} /(\lambda)_{\text {in }}, K_{\text {out }} /(\lambda)_{\text {out }}\right.$, $K$ : 熱伝達率，（），，（）out：殼の内外表面の特性 值 ], $T_{\mathrm{in}}, T_{\mathrm{out}}$ : 殼の内外表面の温度, $h$ : 殼厚である.

傾斜機能材料から成る殼では, 耐熱材として機能す る構成材料の熱伝導率が比較的小さいため, 応答初期 には殼厚方向に局所的にこう配の急な温度分布を生じ る.そこで解の精度の向上を図るため, 次式のように $\zeta$ に関する $p$ 次曲線で殼厚方向の温度分布を表す。

$$
T(\xi, \theta, \zeta, t)=\sum_{j=0}^{p} T_{j}(\xi, \theta, t) \zeta^{j}
$$

式(4)を式(2)に代入し，両辺に $\zeta^{i}(i=0,1,2, \cdots$, p）を掛けて全款厚にわたって積分した $(p+1)$ 個の式 は，殼の内外表面の熱伝達による温度境界条件式 (3) を考慮し，さらに近似式

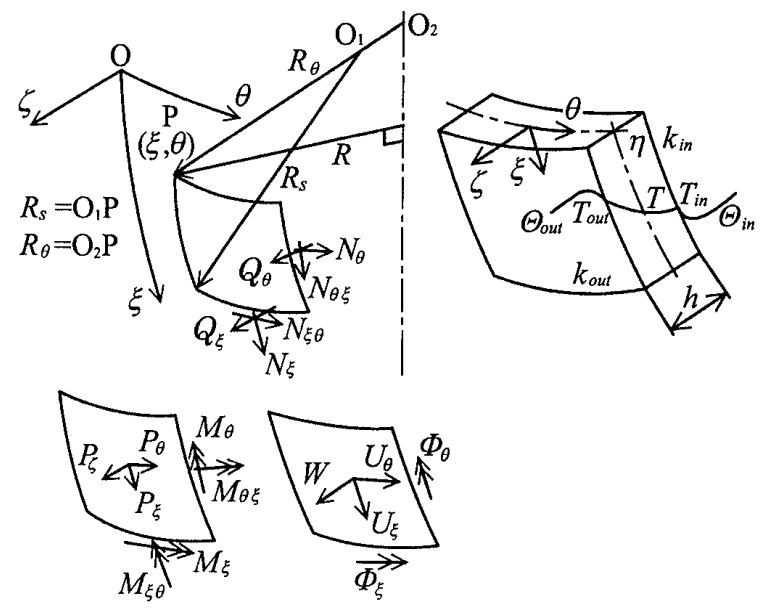

Fig. 1 Coordinates and notations

$$
\left.\begin{array}{l}
\frac{L_{\theta}}{L_{\xi}} \simeq 1+\left(\omega_{\theta}-\omega_{\xi}\right) \frac{\zeta}{a}+\omega_{\xi}\left(\omega_{\xi}-\omega_{\theta}\right) \frac{\zeta^{2}}{a^{2}} \\
\frac{L_{\theta}}{L_{\xi}^{2}} \simeq 1+\left(\omega_{\theta}-2 \omega_{\xi}\right) \frac{\zeta}{a}+\left(3 \omega_{\xi}^{2}-2 \omega_{\xi} \omega_{\theta}\right) \frac{\zeta^{2}}{a^{2}}
\end{array}\right\}
$$

を用いると，次のようになる.

$$
\left.\begin{array}{l}
\sum_{j=0}^{p}\left\{\alpha_{(i, j)} \frac{\partial T_{j}}{\partial t}-\left(\beta_{(i, j)} \frac{\partial T_{j}}{\partial \xi}+\gamma_{(i, j)} \frac{\partial^{2} T_{j}}{\partial \xi^{2}}\right.\right. \\
\left.\left.\quad+\delta_{(i, j)} \frac{\partial^{2} T_{j}}{\partial \theta^{2}}\right)-\varepsilon_{(i, j)} T_{j}\right\}-\mu_{(i)} \Theta_{\mathrm{out}}-\nu_{(i)} \Theta_{\mathrm{ln}} \\
\quad-Q_{i}=0,(i=0,1,2, \cdots, p)
\end{array}\right\}
$$

ここで

$$
\begin{aligned}
\alpha_{(i, j)} & =\left[\left\{1+(-1)^{i+j}\right\}\left(\frac{1}{i+j+1}+\frac{h^{2} \omega_{\xi} \omega_{\theta}}{4 a^{2}(i+j+3)}\right)\right. \\
& \left.+\left\{1-(-1)^{i+j}\right\} \frac{h\left(\omega_{\xi}+\omega_{\theta}\right)}{2 a(i+j+2)}\right]\left(\frac{h}{2}\right)^{i+j+1}, \\
\beta_{(i, j)} & =\frac{1}{a^{2}} \int_{-h / 2}^{h / 2} \chi \zeta^{i+j}\left\{\gamma-\frac{\omega_{\xi}^{\prime}}{a}\left(\zeta+\frac{\omega_{\theta}-2 \omega_{\xi}}{a} \zeta^{2}\right.\right. \\
& \left.\left.+\frac{3 \omega_{\xi}^{3}-2 \omega_{\xi} \omega_{\theta}}{a^{2}} \zeta^{3}\right)\right\} d \zeta, \\
\gamma_{(i, j)} & =\frac{1}{a^{2}} \int_{-h / 2}^{h / 2} \chi \zeta^{i+j}\left(1+\frac{\omega_{\theta}-\omega_{\xi}}{a} \zeta\right. \\
& \left.+\frac{\omega_{\xi}\left(\omega_{\xi}-\omega_{\theta}\right)}{a^{2}} \zeta^{2}\right) d \zeta, \\
\delta_{(i, j)} & =\frac{1}{a^{2} r^{2}} \int_{-h / 2}^{h / 2} \chi \zeta^{i+j}\left(1+\frac{\omega_{\xi}-\omega_{\theta}}{a} \zeta\right. \\
+ & \left.\frac{\omega_{\theta}\left(\omega_{\theta}-\omega_{\xi}\right)}{a^{2}} \zeta^{2}\right) d \zeta, \\
\varepsilon_{(i, j)} & =\bar{\alpha}_{(i, j)}+\frac{\omega_{\xi}+\omega_{\theta}}{a}\left(\bar{\alpha}_{(i+1, j)}+\bar{\beta}_{(i, j)}\right) \\
& +\frac{\omega_{\xi}\left(\omega_{\theta}\right.}{a^{2}\left(\bar{\alpha}_{(i+2, j)}+2 \bar{\beta}_{(i+1, j)}\right),} \\
\bar{\alpha}_{(i, j)} & =-(\chi)_{\text {out }}\left(\frac{h}{2}\right)^{i+j} k_{\text {out }}-(\chi)_{\text {In }}\left(-\frac{h}{2}\right)^{i+j} k_{\text {in }} \\
& +\left\{\left(\frac{1}{c \rho} \frac{\partial \lambda}{\partial \zeta}\right)_{\text {out }}\left(\frac{h}{2}\right)^{i}-\left(\frac{\partial\left(\chi \zeta^{i}\right)}{\partial \zeta}\right)_{\text {out }}\right\}\left(\frac{h}{2}\right)^{j}
\end{aligned}
$$




$$
\begin{gathered}
-\left\{\left(\frac{1}{c \rho} \frac{\partial \lambda}{\partial \zeta}\right)_{\text {in }}\left(-\frac{h}{2}\right)^{i}-\left(\frac{\partial\left(\chi \zeta^{i}\right)}{\partial \zeta}\right)_{\text {in }}\right\}\left(-\frac{h}{2}\right)^{j} \\
+\int_{-h / 2}^{h / 2}\left\{\frac{\partial^{2}\left(\chi \zeta^{i}\right)}{\partial \zeta^{2}}-\frac{\partial}{\partial \zeta}\left(\frac{\zeta^{i}}{c \rho} \frac{\partial \lambda}{\partial \zeta}\right)\right\} \zeta^{j} d \zeta, \\
\bar{\beta}_{(i, j)}=\left\{(\chi)_{\text {out }}\left(\frac{h}{2}\right)^{i+j}-(\chi)_{\text {in }}\left(-\frac{h}{2}\right)^{i+j}\right\} \\
-\int_{-h / 2}^{h / 2} \frac{\partial\left(\chi \zeta^{i}\right)}{\partial \zeta} \zeta^{j} d \zeta, \\
\mu_{(i)}=(\chi)_{\text {out }}\left(\frac{h}{2}\right)^{i}\left\{1+\frac{h\left(\omega_{\xi}+\omega_{\theta}\right)}{2 a}+\frac{h^{2} \omega_{\xi} \omega_{\theta}}{4 a^{2}}\right\} k_{\text {out }}, \\
\nu_{(i)}=(\chi)_{\text {in }}\left(-\frac{h}{2}\right)^{i}\left\{1-\frac{h\left(\omega_{\xi}+\omega_{\theta}\right)}{2 a}+\frac{h^{2} \omega_{\xi} \omega_{\theta}}{4 a^{2}}\right\} k_{\mathrm{ln}}
\end{gathered}
$$

また，

$$
Q_{i}=\int_{-h / 2}^{h / 2} \frac{\eta}{c \rho} \zeta^{i}\left(1+\frac{\omega_{\xi}+\omega_{\theta}}{a} \zeta+\frac{\omega_{\xi} \omega_{\theta}}{a^{2}} \zeta^{2}\right) d \zeta
$$

以上で $(p+1)$ 個の未知数 $T_{j}(j=0,1,2, \cdots, p)$ に対 して, 式 (6)が与えられ，これを解くと殼の温度分布 が求められる。

$2 \cdot 2$ 熱変形方程式回転対称殻の運動方程式な らびにひずみと中央面の変位・回転との関係には, 殼 厚方向のせん断変形を考慮した Reissner-Naghdi の 款理論式(9)(10) を採用する。これらの基礎式は, 既発表 の論文中の諸式(11) と同一なので, ここでは紙面の都 合もあり列挙するに止める。なお式中の $\Delta$ は増分を 表す。

$\bigcirc$ 軸対称款の運動方程式：

$$
\begin{aligned}
& \frac{\partial\left(\Delta N_{\xi}\right)}{\partial \xi}+\gamma\left(\Delta N_{\xi}-\Delta N_{\theta}\right)+\frac{1}{r} \frac{\partial\left(\Delta N_{\theta \xi}\right)}{\partial \theta} \\
& +\omega_{\xi} \Delta Q_{\xi}+a\left[\Delta P_{\xi}-\bar{\rho} h \frac{\partial^{2}\left(\Delta U_{\xi}\right)}{\partial t^{2}}\right]=0 \\
& \frac{\partial\left(\Delta N_{\xi \theta}\right)}{\partial \xi}+\gamma\left(\Delta N_{\xi \theta}+\Delta N_{\theta \xi}\right)+\frac{1}{r} \frac{\partial\left(\Delta N_{\theta}\right)}{\partial \theta} \\
& +\omega_{\theta} \Delta Q_{\theta}+a\left[\Delta P_{\theta}-\bar{\rho} h \frac{\partial^{2}\left(\Delta U_{\theta}\right)}{\partial t^{2}}\right]=0 \\
& \frac{\partial\left(\Delta Q_{\xi}\right)}{\partial \xi}+\gamma \Delta Q_{\xi}+\frac{1}{r} \frac{\partial\left(\Delta Q_{\theta}\right)}{\partial \theta} \\
& -\left(\omega_{\xi} \Delta N_{\xi}+\omega_{\theta} \Delta N_{\theta}\right) \\
& +a\left[\Delta P_{\xi}-\bar{\rho} h \frac{\partial^{2}(\Delta W)}{\partial t^{2}}\right]=0 \\
& \Delta Q_{\xi}-\frac{1}{a}\left[\frac{\partial\left(\Delta M_{\xi}\right)}{\partial \xi}+\gamma\left(\Delta M_{\xi}-\Delta M_{\theta}\right)\right. \\
& \left.\quad+\frac{1}{r} \frac{\partial\left(\Delta M_{\theta \xi}\right)}{\partial \theta}\right]=0 \\
& \Delta Q_{\theta}-\frac{1}{a}\left[\frac{\partial\left(\Delta M_{\xi \theta}\right)}{\partial \xi}+\gamma\left(\Delta M_{\xi \theta}+\Delta M_{\theta \xi}\right)\right. \\
& \left.\quad+\frac{1}{r} \frac{\partial\left(\Delta M_{\theta}\right)}{\partial \theta}\right]=0
\end{aligned}
$$

$\left.N_{\tilde{\xi} \theta}, N_{\theta \xi}, Q_{\xi}, Q_{\theta}\right\}(=\{N\}), \quad\left\{M_{\xi}, M_{\theta}, M_{\xi \theta}, M_{\theta \xi}\right\}(=$ $\{M\})$ : 殸の単位長さ当たりの合応力および合モーメ ント, $U_{\xi}, U_{\theta}, W$ : 壳の中央面の $\xi, \theta, \zeta$ 方向変位, $P_{\xi}, P_{\theta}, P_{\zeta}$ : 殼の中央面の単位面積当たりの分布荷重 である(図 1)。

○中央面のひずみと変位の関係：

$$
\left.\begin{array}{l}
\Delta \varepsilon_{\xi m}=\frac{1}{a}\left[\frac{\partial \Delta U_{\xi}}{\partial \xi}+\omega_{\xi} \Delta W\right] \\
\Delta \varepsilon_{\theta m}=\frac{1}{a}\left[\frac{1}{r} \frac{\partial \Delta U_{\theta}}{\partial \theta}+\gamma \Delta U_{\xi}+\omega_{\theta} \Delta W\right] \\
\Delta \varepsilon_{\xi \theta m}=\frac{1}{2 a}\left[\frac{1}{r} \frac{\partial \Delta U_{\xi}}{\partial \theta}+\frac{\partial \Delta U_{\theta}}{\partial \xi}-\gamma \Delta U_{\theta}\right]
\end{array}\right\}
$$

○曲率の変化量と変位成分の関係：

$$
\left.\begin{array}{l}
\Delta \varkappa_{\xi}=\frac{1}{a} \frac{\partial \Delta \Phi_{\xi}}{\partial \xi}, \Delta \varkappa_{\theta}=\frac{1}{a}\left(\frac{1}{r} \frac{\partial \Delta \Phi_{\theta}}{\partial \theta}+\gamma \Delta \Phi_{\xi}\right) \\
\Delta \varkappa_{\xi \theta}=\frac{1}{2 a}\left(\frac{\partial \Delta \Phi_{\theta}}{\partial \xi}-2 \omega_{\xi} \Delta \Phi_{n}\right) \\
\Delta \varkappa_{\theta \xi}=\frac{1}{2 a}\left(\frac{1}{r} \frac{\partial \Delta \Phi_{\xi}}{\partial \theta}-\gamma \Delta \Phi_{\theta}+2 \omega_{\theta} \Delta \Phi_{n}\right)
\end{array}\right\}
$$

○中央面の回転と変位・ひずみの関係：

$$
\left.\begin{array}{l}
\Delta \Phi_{\xi}=\frac{1}{a}\left(-\frac{\partial \Delta W}{\partial \xi}+\omega_{\xi} \Delta U_{\xi}\right)+2 \Delta \varepsilon_{\xi \zeta m} \\
\Delta \Phi_{\theta}=\frac{1}{a}\left(-\frac{1}{r} \frac{\partial \Delta W}{\partial \theta}+\omega_{\theta} \Delta U_{\theta}\right)+2 \Delta \varepsilon_{\theta \zeta m} \\
\Delta \Phi_{n}=\frac{1}{2 a}\left(-\frac{1}{r} \frac{\partial \Delta U_{\xi}}{\partial \theta}+\frac{\partial \Delta U_{\theta}}{\partial \xi}+\gamma \Delta U_{\theta}\right)
\end{array}\right\}
$$

○款厚中央面から $\zeta$ 距離にある点のひずみ：

$$
\begin{aligned}
\Delta \varepsilon_{\xi} & =\left(\Delta \varepsilon_{\xi m}+\zeta \Delta \varkappa_{\xi}\right) / L_{\xi} \\
\Delta \varepsilon_{\theta} & =\left(\Delta \varepsilon_{\theta m}+\zeta \Delta \varkappa_{\theta}\right) / L_{\theta} \\
\Delta \varepsilon_{\xi \theta} & =\left\{\frac{1}{2}\left(\Delta \varepsilon_{\xi \theta m}+\Delta \Phi_{n}\right)\right. \\
& \left.+\zeta\left(\Delta \varkappa_{\xi \theta}+\frac{\omega_{\xi}}{a} \Delta \Phi_{n}\right)\right\} / L_{\xi}+\left\{\frac{1}{2}\left(\Delta \varepsilon_{\xi \theta m}-\Delta \Phi_{n}\right)\right. \\
& \left.+\zeta\left(\Delta \varkappa_{\theta \xi}-\frac{\omega_{\theta}}{a} \Delta \Phi_{n}\right)\right\} / L_{\theta} \\
\Delta \varepsilon_{\xi \zeta} & =\Delta \varepsilon_{\xi \zeta m} / L_{\xi}, \Delta \varepsilon_{\theta \xi}=\Delta \varepsilon_{\theta \zeta m} / L_{\theta}
\end{aligned}
$$

さて, 款厚方向の垂直応力 $\sigma_{\xi}=0$ の応力状態を仮定 すると, 応力増分は式(13)を用いて次式のようになる.

$\{\Delta \sigma\}=[D]\{\Delta \varepsilon\}-\left\{\Delta \sigma^{t}\right\}$

ここで, $\bar{\rho}$ : 殸厚方向の密度分布の平均值, $\left\{N_{\xi}, N_{\theta}\right.$, 


$$
\begin{aligned}
& \{\Delta \sigma\}=\left\{\Delta \sigma_{\xi}, \Delta \sigma_{\theta}, \Delta \sigma_{\xi \theta}, \Delta \sigma_{\xi \zeta}, \Delta \sigma_{\theta \xi}\right\}^{T} \\
& \{\Delta \varepsilon\}=\left\{\Delta \varepsilon_{\xi}, \Delta \varepsilon_{\theta}, \Delta \varepsilon_{\xi \theta}, \Delta \varepsilon_{\xi \xi}, \Delta \varepsilon_{\theta \xi}\right\}^{T} \\
& \left\{\Delta \sigma^{t}\right\}=\left\{\Delta \sigma^{t}, \Delta \sigma^{t}, 0,0,0\right\}^{T} \\
& =\frac{\alpha E}{1-\nu}\left\{\Delta T_{e}, \Delta T_{e}, 0,0,0\right\}^{T} \\
& \left.[D]=\frac{E}{1-\nu^{2}}\left[\begin{array}{ccccc}
1 & \nu & 0 & 0 & 0 \\
\nu & 1 & 0 & 0 & 0 \\
0 & 0 & 1-\nu & 0 & 0 \\
0 & 0 & 0 & 1-\nu & 0 \\
0 & 0 & 0 & 0 & 1-\nu
\end{array}\right]\right\}
\end{aligned}
$$

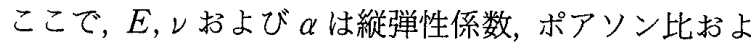
び線膨張係数であり, \{\}$^{T}$ は転置行列を表す. $T_{e}$ は 基準温度 $\bar{T}_{0}$ からの温度変化で, 時刻 $t$ におけ殼の 任意点の温度を $T$ とすると，

$$
T_{e}(\xi, \theta, \zeta, t)=T(\xi, \theta, \zeta, t)-\bar{T}_{0}
$$
となる。

式(13)，(14）を用いると，殼の単位長さ当たりの合 応力 $\{N\}$ および合モーメント $\{M\}$ は次のようになる。

$$
\begin{aligned}
& \Delta N_{\xi}=\int_{-h / 2}^{h / 2} \frac{E}{1-\nu^{2}}\left\{\left(\Delta \varepsilon_{\xi m}+\zeta \Delta \varkappa_{\xi}\right) \frac{L_{\theta}}{L_{\xi}}\right. \\
& \left.+\nu\left(\Delta \varepsilon_{\theta m}+\zeta \Delta \varkappa_{\theta}\right)\right\} d \zeta-\Delta N_{\xi}^{t} \\
& \Delta N_{\xi \theta}=\int_{-n / 2}^{h / 2} \frac{E}{1+\nu}\left[\left\{\frac{1}{2}\left(\Delta \varepsilon_{\xi \theta m}+\Delta \Phi_{n}\right)\right.\right. \\
& \left.\quad+\zeta\left(\Delta \varkappa_{\xi \theta}+\frac{\omega_{\xi}}{a} \Delta \Phi_{n}\right)\right\} \frac{L_{\theta}}{L_{\xi}}+\frac{1}{2}\left(\Delta \varepsilon_{\xi \theta m}-\Delta \Phi_{n}\right) \\
& \left.\quad+\zeta\left(\Delta \varkappa_{\theta \xi}-\frac{\omega_{\theta}}{a} \Delta \Phi_{n}\right)\right] d \zeta \\
& \Delta Q_{\xi}=\frac{5}{6} \int_{-h / 2}^{h / 2} \frac{E}{1+\nu} \Delta \varepsilon_{\xi \zeta m} \frac{L_{\theta}}{L_{\xi}} d \zeta \\
& \Delta M_{\xi}=\int_{-h / 2}^{h / 2} \frac{E}{1-\nu^{2}}\left\{\left(\Delta \varepsilon_{\xi m}+\zeta \Delta \varkappa_{\xi}\right) \frac{L_{\theta}}{L_{\xi}}\right. \\
& \left.\quad+\nu\left(\Delta \varepsilon_{\theta m}+\zeta \Delta \varkappa_{\theta}\right)\right\} \zeta d \zeta-\Delta M_{\xi}^{t} \\
& \Delta M_{\xi \theta}=\int_{-h / 2}^{h / 2} \frac{E}{1+\nu}\left[\left\{\frac{1}{2}\left(\Delta \varepsilon_{\xi \theta m}+\Delta \Phi_{n}\right)\right.\right. \\
& \left.\quad+\zeta\left(\Delta \varkappa_{\xi \theta}+\frac{\omega_{\xi}}{a} \Delta \Phi_{n}\right)\right\} \frac{L_{\theta}}{L_{\xi}}+\frac{1}{2}\left(\Delta \varepsilon_{\xi \theta m}-\Delta \Phi_{n}\right) \\
& \left.\quad+\zeta\left(\Delta \varkappa_{\theta \xi}-\frac{\omega_{\theta}}{a} \Delta \Phi_{n}\right)\right] \zeta d \zeta
\end{aligned}
$$

ここで, ()$^{t}$ は温度変化 $T_{e}$ による内力成分を示し, 次式によって熱応力増分から計算できる.

$$
\left\{\Delta N_{\xi}^{t}, \Delta M_{\xi}^{t}\right\}=\int_{-h / 2}^{h / 2} \frac{\alpha E}{1-\nu}\left\{\Delta T_{e}, \Delta T_{e} \zeta\right\} L_{\theta} d \zeta
$$

なお, $\Delta N_{\theta}, \Delta N_{\theta \xi}, \Delta Q_{\theta}, \Delta M_{\theta}, \Delta M_{\theta \xi}$ お よ゙゙ $\Delta N_{\theta}^{t}, \Delta M_{\theta}^{t}$ は，それぞれ $\Delta N_{\xi}, \Delta N_{\xi \theta}, \Delta Q_{\xi}, \Delta M_{\xi}, \Delta M_{\xi \theta}$ および $\Delta N_{\xi}^{t}$ $\Delta M_{\xi}^{t}$ の式中の添字 $\xi$ と $\theta$ を置き換え, また $\Delta \Phi_{n}$ の正 負の符号を変えたものである。
以上で 30 個の未知数 $\{\Delta N\},\{\Delta M\}, \Delta U_{\xi}, \Delta U_{\theta}, \Delta W$, $\Delta \varepsilon_{\xi m}, \Delta \varepsilon_{\theta m}, \Delta \varepsilon_{\xi \theta m}, \Delta \varepsilon_{\xi \zeta m}, \Delta \varepsilon_{\theta \zeta m}, \Delta \varkappa_{\xi}, \Delta \varkappa_{\theta}, \Delta \varkappa_{\xi \theta}, \Delta \varkappa_{\theta \xi}$, $\Delta \Phi_{\xi}, \Delta \Phi_{\theta}, \Delta \Phi_{n}, \Delta \sigma^{t}, \Delta N_{\xi}^{t}, \Delta N_{\theta}^{t}, \Delta M_{\xi}^{t}, \Delta M_{\theta}^{t}$ に対して式 (9)〜(12)，(15)，(17)，(18)の30 個の式が得られた ことになる。

\section{3. 無次元方程式と数値計算法}

一般に非軸対称問題を解析するには，各変数を $\theta$ 方 向にフーリエ級数で表し，その係数を定めればよい. そこで, 2 章に示した $(p+31)$ 個の変数と分布荷重, 款の内外の周囲温度および発熱量をフーリ工級数に展 開する(11)(12). これらのフーリ工展開式を前述の基礎 式に代入し，フーリエ係数(対応する小文字を用いる) に関する式をつくると，熱伝導方程式から $t_{j}^{(n)}(j=0$, $1,2, \cdots, p ; n:$ フーリ工指数)に関する次の $(p+1)$ 元 連立 2 階微分方程式が得られる。

$$
A_{1} Y^{\prime \prime}+A_{2} Y^{\prime}+A_{3} Y=A_{4}+A_{5}(\partial Y / \partial \tau)
$$

ただし $Y=\left\{t_{0}^{(n)}, t_{1}^{(n)}, t_{2}^{(n)}, \cdots, t_{p}^{(n)}\right\}^{T}, \tau=\chi_{0} t / a^{2}\left(\chi_{0}:\right.$ 代 表温度伝導率 $\left[=\lambda_{0} /\left(c_{0} \rho_{0}\right)\right], \lambda_{0}$ : 代表熱伝導率, $c_{0}$ : 代表比熱, $\rho_{0}$ ：代表密度)である.ここで $A_{1} \sim A_{3}$ は 殸の形状, 温度伝導率および款の内外表面の相対熱伝 達率から定まる $(p+1) \times(p+1)$ の定数行列であり， $A_{4}$ はさらに殼の内外の周囲温度ならびに発熱量から 定まる $(p+1) \times 1$ の定数行列である。また $A_{5}$ も（ $p$ $+1) \times(p+1)$ の定数行列である。

次に, 殼の熱変形方程式は未知数を順次消去するこ とにより, 変位増分 $\Delta u_{\xi}^{(n)}, \Delta u_{\theta}^{(n)}, \Delta W^{(n)}$ および回転増 分 $\Delta \phi_{\xi}^{(n)}, \Delta \phi_{\theta}^{(n)}$ に関寸る次の 5 元連立 2 階微分方程式 になる。

$$
B_{1} Z^{\prime \prime}+B_{2} Z^{\prime}+B_{3} Z=B_{4}+\bar{Z}
$$

ただし $Z=\left\{\Delta u_{\xi}^{(n)}, \Delta u_{\theta}^{(n)}, \Delta w^{(n)}, \Delta \phi_{\xi}^{(n)}, \Delta \phi_{\theta}^{(n)}\right\}^{T}, \bar{Z}=$ $\left\{\partial^{2} \Delta u_{\xi}^{(n)} / \partial \tau^{2}, \partial^{2} \Delta u_{\theta}^{(n)} / \partial \tau^{2}, \partial^{2} \Delta w^{(n)} / \partial \tau^{2}, 0,0\right\}^{T}$. ここで, $B_{1} \sim B_{3}$ は殼の形状と材料定数 $(E, \nu)$ の值から定まる $5 \times 5$ の定数行列であり，また $B_{4}$ は殼の形状のほかに， 分布荷重および温度負荷による内力成分から定まる 5 $\times 1$ の定数行列である。

さて，ある任意の計算段階における温度と，変位な らびに回転の増分とは，式(19)と式(20)を適当な境界 条件のもとで解けば得られ，またこれらを用いて内力 成分の増分は，式(10)〜 (12) を式(17)に代入したもの から求められる、しかしながら, 式(19)と式(20)を厳 密に理論解析することは困難であるから, 差分法によ つて数值的に解を求める(12). なお慣性項には Houbolt の後退差分式(13) を用い, 款厚方向の積分に は，等間隔に格子点を取ってシンプソンの $1 / 3$ 則を適 用する。 


\section{4. 数 值 解 析 例}

数值解析例として, 殼厚方向に不均質性を有する厚 肉円筒殼を取り上げ，円筒殼内表面に流体加熱が時間 に対してステップ状に作用する問題と，円筒殼中央部 に内部発熱による衝撃熱負荷が時間に対してインパル ス状に作用する問題を解析した。円筒殼の厚さは, 殼 厚方向のせん断変形の影響は考慮するが, 款厚方向の 垂直応力は無視するという殼理論の適用限界を考元 $\tau, h / R=1 / 5$ とした.

計算に用いた円筒殼の材料定数には, 次の SUS 304 と $\mathrm{ZrO}_{2}$ の値を用いた。

O SUS 304

$$
\left.\begin{array}{l}
E_{s}=170 \mathrm{GPa}, \nu_{s}=0.3 \\
\rho_{s}=7.8 \mathrm{~g} / \mathrm{cm}^{3}, \lambda_{s}=19 \mathrm{~W} /\left(\mathrm{m} \cdot{ }^{\circ} \mathrm{C}\right) \\
c_{s}=0.56 \mathrm{~kJ} /\left(\mathrm{kg} \cdot{ }^{\circ} \mathrm{C}\right) \\
\alpha_{s}=18 \times 10^{-6} 1 /{ }^{\circ} \mathrm{C}
\end{array}\right\}
$$

$\bigcirc \mathrm{ZrO}_{2}$

$$
\left.\begin{array}{l}
E_{z}=210 \mathrm{GPa}, \nu_{z}=0.32 \\
\rho_{z}=5.9 \mathrm{~g} / \mathrm{cm}^{3}, \lambda_{z}=3 \mathrm{~W} /\left(\mathrm{m} \cdot{ }^{\circ} \mathrm{C}\right) \\
c_{z}=0.3 \mathrm{~kJ} /\left(\mathrm{kg} \cdot{ }^{\circ} \mathrm{C}\right) \\
\alpha_{z}=10 \times 10^{-6} 1 /{ }^{\circ} \mathrm{C}
\end{array}\right\}
$$

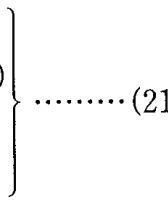

二つの例題とも式(18)の熱応力の積分にはシンプソン
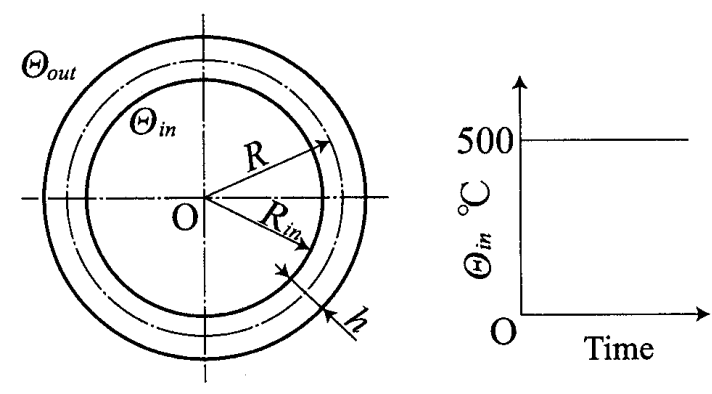

$$
\begin{aligned}
& R=200 \mathrm{~mm}, \quad h=40 \mathrm{~mm} \\
& K_{\text {out }}=K_{\text {in }}=10^{11} \mathrm{~W} /\left(\mathrm{m}^{2} \cdot{ }^{\circ} \mathrm{C}\right)
\end{aligned}
$$

Fig. 2 Numerical example 1

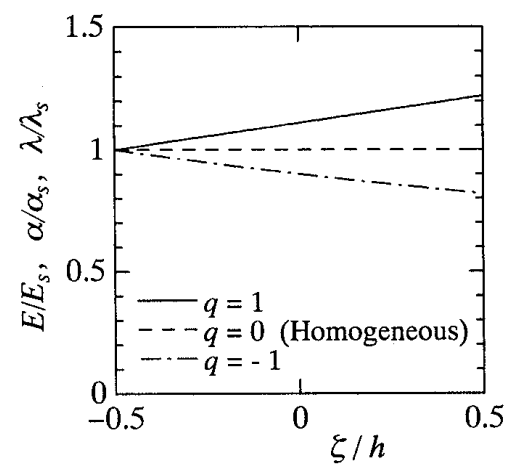

Fig. 3 Nonhomogeneity of material constants through thickness
の $1 / 3$ 則を用い, 殼厚方向に 19 個の格子点を採用し て数値計算を行った，式 (7)，(17)などの材料定数の 殼厚方向の数値積分には，含まれる て, 最大 1024 個の格子点を用いた。時間増分は例題 1 で $0.01 \mu \mathrm{s}$, 例題 2 で $10 \mu \mathrm{s}$ と，例 2 で取り上げた 冈筒殼の子午線方向の差分点数は 601 とした．また殸 厚方向の温度分布曲線を表す多項式の次数 $p$ は, 例 1 で10, 例 2 の Case 1，2，3で各々 4, 8, 1 とした.こ れらの值は解の収束性を考慮して決定した。

$4 \cdot 1$ 例題 1 無限長円筒殼の内表面に, 一様な流 体加熱が時間に対してステップ状に作用する問題（図 2)を取り上げ，温度分布・熱応力解析を行って，須見

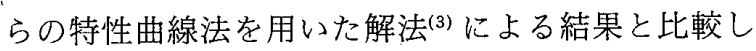
た。な抢須見らは円筒の内面を直接急加熱する場合を 計算しているが，ここでは内部流体の温度 $\Theta_{\mathrm{In}}$ を与え， 熱伝達により加熱する場合を取扱った。

本計算でも須見らと同様に, 縱弾性係数, 線膨張係 数, 熱伝導率の不均質性に比べて, 密度, ポアソン比, 比熱の不均質性は小さいものとして, 殼体内でこれら を一定とした。また, 縦弾性係数, 線膨張係数および 熱伝導率は半径方向に $(R+\zeta)$ のべき乗で組成分布を 与交た。

$$
\left.\begin{array}{l}
\rho=\rho_{s}, c=c_{s}, \nu=\nu_{s} \\
E=E_{s}\left\{(R+\zeta) / R_{\mathrm{in}}\right\}^{q} \\
\alpha=\alpha_{s}\left\{(R+\zeta) / R_{\mathrm{in}}\right\}^{q} \\
\lambda=\lambda_{s}\left\{(R+\zeta) / R_{\mathrm{in}}\right\}^{q}
\end{array}\right\}
$$

なお，指数 $q$ は $1,0,-103$ 種類とし(図 3), $q=0$ は 均質材料に対応する. 本計算例では, 本解法を須見ら の特性曲線法による解法と比較するのが目的であるか ら, 動的効果を明りょうにするため, 熱伝導率 $\lambda_{s}$ と殸 の内外表面の熱伝達率 $K$ を仮想的に大きくとり, $\lambda_{s}$ $=8.52 \times 10^{8} \mathrm{~W} /\left(\mathrm{m} \cdot{ }^{\circ} \mathrm{C}\right), K_{\text {in }}=K_{\text {out }}=10^{11} \mathrm{~W} /\left(\mathrm{m}^{2} \cdot{ }^{\circ} \mathrm{C}\right)$ とした.

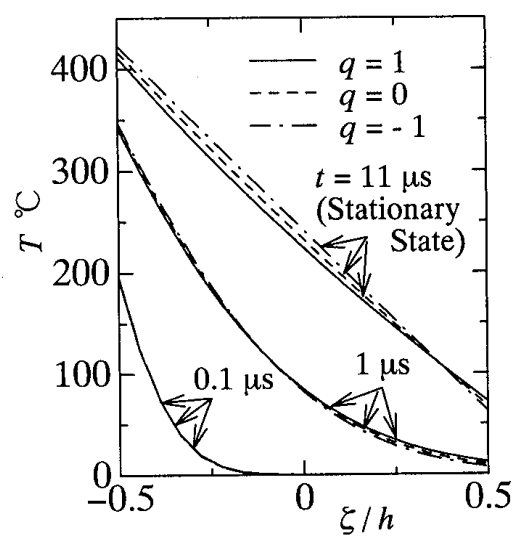

Fig. 4 Temperature distributions through thickness 
図 4 は款厚方向の温度分布の時間的変化を，また図 5 は内外表面ならびに中央面の温度の時間的変化を示 したものである. 熱負荷後およそ $11 \mu \mathrm{S} て ゙$ 定常状態に 至り, 高温側 (内表面側) 加ら低温側 (外表面側) に熱伝 導率が小さくなる $q=-1$ の不均質殼の場合は, 他の $q=0,1$ の場合に比べて殼厚方向の温度差が大きくな る.

次に, 円筒款中央面の半径方向変位 $W$ の時間的変 化を図 6 に示す. 図中本解法による結果を破線で, ま た須見らの特性曲線法による解を実線で示す。なお $q$ $=0$ の特性曲線法による結果は, $q= \pm 1$ の場合と同様 の傾向を示すので, 図の煩雑さを避けるために省略し た. 殼の平均緃弾性係数と線膨張係数が大きくなるほ ど, 殼の変動周期は短く,また振幅は大きくなってい る. 須見らの厚肉円筒に対する特性曲線法による解 は，応力波の反射・干涉等の伝ぱ挙動を考慮している ため, 本解法で得られた変位 $W$ の変動に, 微小な振 幅と周期の波動が重畳した結果となっている。雨結果 は極大, 極小值にわずかな差が見られる程度で, よく 一致している.

図 7 は $q=1$ の場合の円筒殼内外表面抢よび中央面 に生ずる円周方向応力 $\sigma_{\theta}$ の時間的変化を示したもの

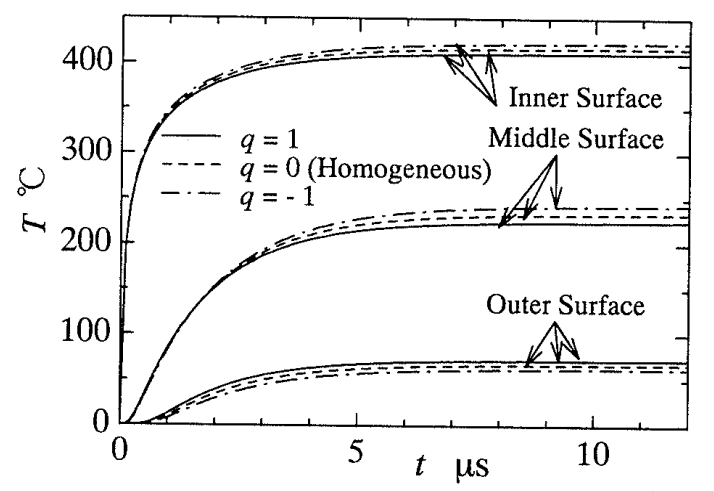

Fig. 5 Variations of temperature with time

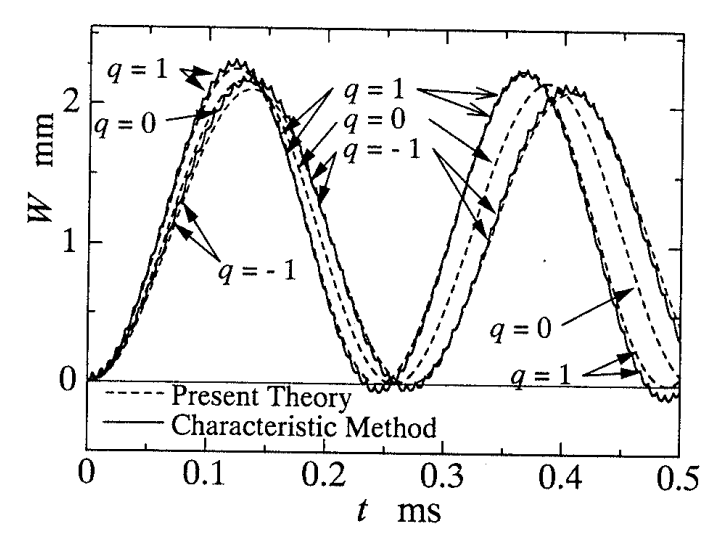

Fig. 6 Variations of displacement $W$ with time
である、破線は本解法による結果であり，実線は特性 曲線法による結果で，太い実線は中央面の $\sigma_{\theta}$ を，細い 実線は内外表面の $\sigma_{\theta}$ を表す. 殼の加熱表面近傍では， 熱負荷直後に生ずる殼厚方向の顕著な温度差により大 きな圧縮応力を生じ，その後変位とともに変動する. 特性曲線法による解は, 変位の場合に比べ大きい周期 と振幅の波動が本解法の解に重畳し, 款の中央面で顕 著である，中央面では振幅の中心を，また内外表面で は個々の変動の極大, 極小值を連ねた応答波形が, 本 解法の時間的変化と一致している。これは本計算では 㲄厚方向応力 $\sigma_{\zeta}$ を零とし，また款厚方向のひずみ分 布を式(13)で与えているためと推察される.

$4 \cdot 2$ 例題 2 殼の両端ならびに内外表面を断熱 $(k=0)$ とし，単純可動支持された用筒殻の中央部 ( $\xi$ $\geqq 0.25)$ に, 内部発熱による衝撃熱負荷が時間に対し てインパルス状に作用する問題(図 8)を取り上げた。 円筒款は SUS 304 と $\mathrm{ZrO}_{2}$ で構成され, 壳厚方向に組 成傾斜を示すパラメータとして SUS 304 の体積分率

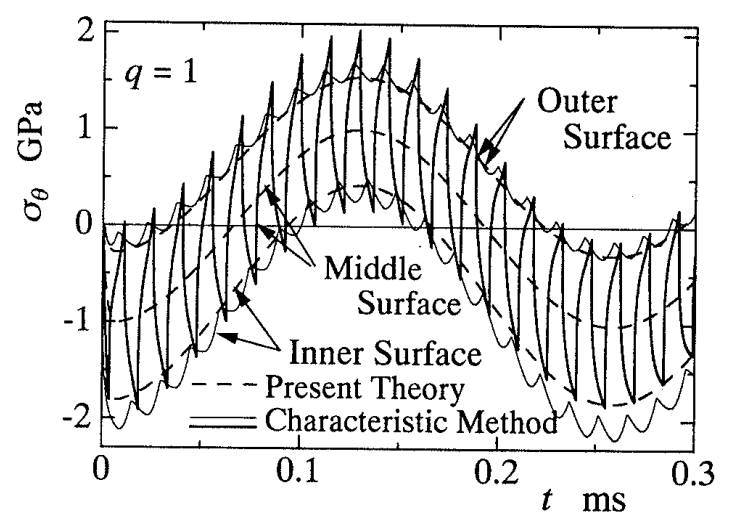

Fig. 7 Variations of stress $\sigma_{\theta}$ with time

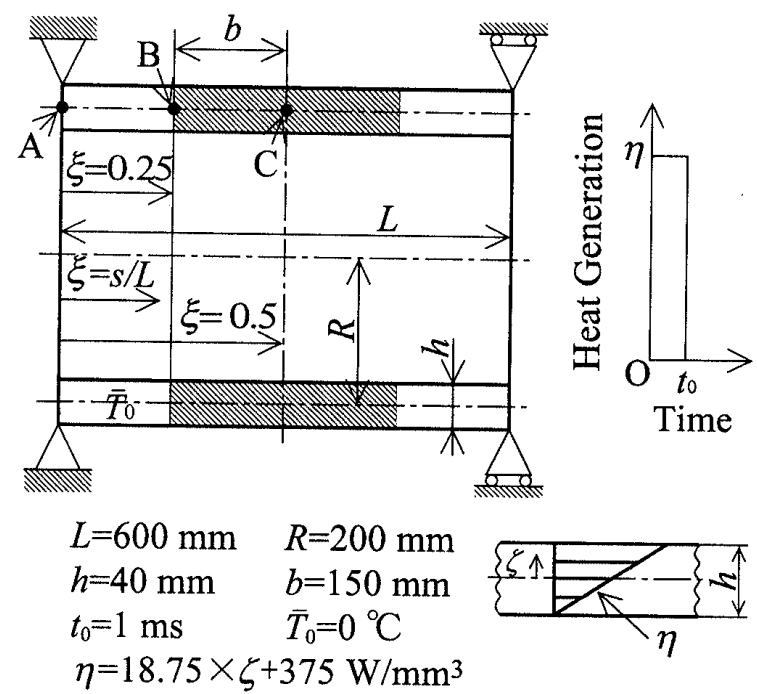

Fig. 8 Numerical example 2 
$V_{s}$ を用いて, 以下の 3 種類の殼厚方向の傾斜を表し た(図 9).

$$
\left.\begin{array}{l}
\text { Case } 1: V_{s}=1-(\zeta / h+0.5) \\
\text { Case 2: } V_{s}=1-(\zeta / h+0.5)^{3} \\
\text { Case } 3: V_{s}=1
\end{array}\right\}
$$

すなわち, Case 1, Case 2 は円筒殼の外表面で $\mathrm{ZrO}_{2}$, 内表面でSUS 304 のみからなり, Case 1 はSUS 304 の体積分率が直線状に変化する場合である。さらに Case 3 はSUS 304 のみの均質円筒殸の場合である. 式(21)，(22)の 6 種類の材料定数について, 壳厚方向 における物性值を，その位置におけるSUS 304 の体 積分率 $V_{S}$ を用いて線形複合則で表現すると，例えば 縦弾性係数 $E(\zeta)$ は次式で表される.

$$
E(\zeta)=E_{z}\left\{1-V_{S}(\zeta)\right\}+E_{S} V_{S}(\zeta)
$$

ここで添字 $S, Z$ は各々SUS 304 と $\mathrm{ZrO}_{2}$ の物性值を 意味する。

次に計算結果について考察する. 図 10 以下, 実線, 破線，および一点鎖線は，それぞれ Case 1〜Case 3 の 結果である。

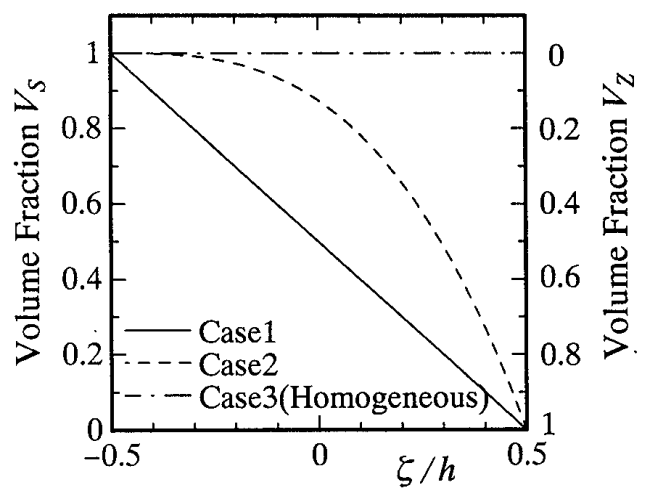

Fig. 9 Volumetric distributions of SUU 304 and $\mathrm{ZrO}_{2}$ through thickness

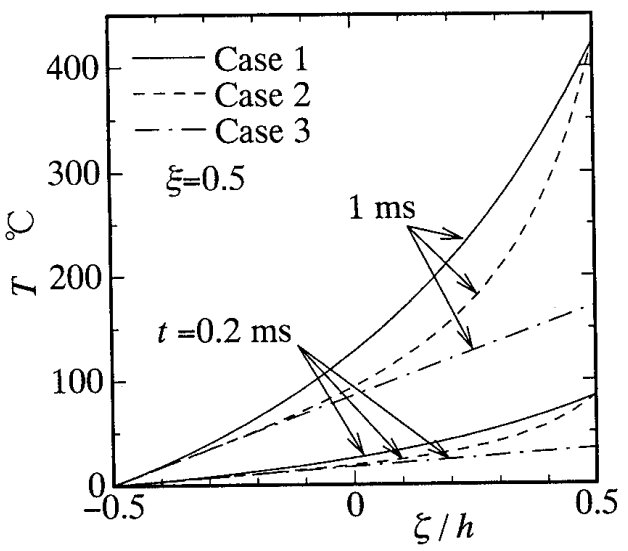

Fig. 10 Temperature distributions through thickness at point $\mathrm{C}$
図 10 は点 $\mathrm{C}(\xi=0.5)$ における殼厚方向の温度分布 の時間的変化を，また図 11 は点 Cの内外表面ならび に中央面の温度の時間的変化を示す。発熱中 $(0<t \leqq$ $1 \mathrm{~ms}$ ) は Case 1 Case 3 とも発熱部の款体温度は時 間にほほ比例して上昇し，発熱終了直後 $(t>1 \mathrm{~ms})$ 加 らは，上昇時と比べて極めて小さな変化率で款体内一 様温度に推移していく．すべての Caseで発熱量は同 一であり，発熱時間を含めた数 $\mathrm{ms}$ の間では熱伝導は 無視され, 温度の上昇速度は密度と比熱の積の值に左 右される. $\mathrm{ZrO}_{2}$ を多く含む円筒款ほど款体内で高温 となる，図には示さなかったが温度の子午線方向分布 は, 発熱時間を含めた数 $\mathrm{ms}$ の間では, 加熱境界(点 $\mathrm{B}: \xi=0.25)$ で子午線方向にほぼステップ状の温度 分布を示し, 非加熱部 $(\xi<0.25)$ は初期温度 $\bar{T}_{0}$ のま まである。

次に, 点 $\mathrm{A}(\xi=0)$ の子午線方向変位 $U_{\xi}$ および点 $\mathrm{C}$ の半径方向変位 $W$ の時間的変化を図 12 に, また時刻 $t=1 \mathrm{~ms}$ のとの $U_{\varepsilon}$ および $W$ の子午線方向分布を 図 13 に示す. 加熱部の温度上昇とともに, 雨変位は 小さな変動を伴いながら増加し, 加熱終了時刻を少し 過ぎて最大となるが, 変形領域は加熱部付近に限られ る.また, SUS 304 の縦弾性係数は $\mathrm{ZrO}_{2}$ より小さく

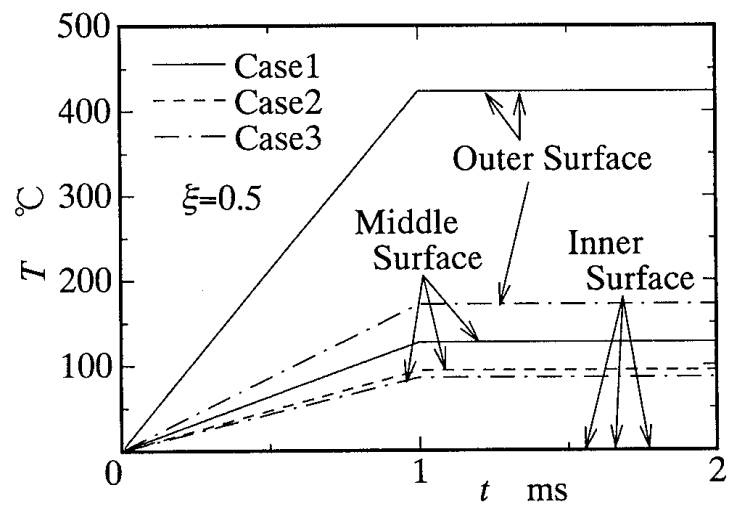

Fig. 11 Variations of temperature at point $\mathrm{C}$ with time

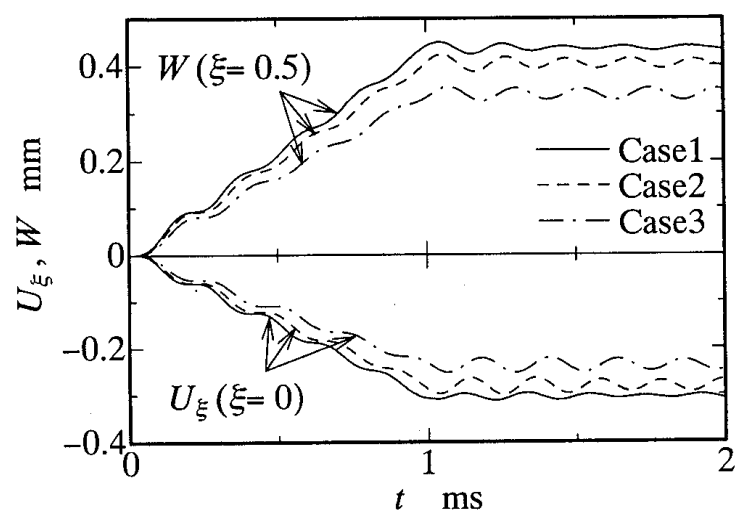

Fig. 12 Variations of displacements $U_{\xi}$ and $W$ with time 


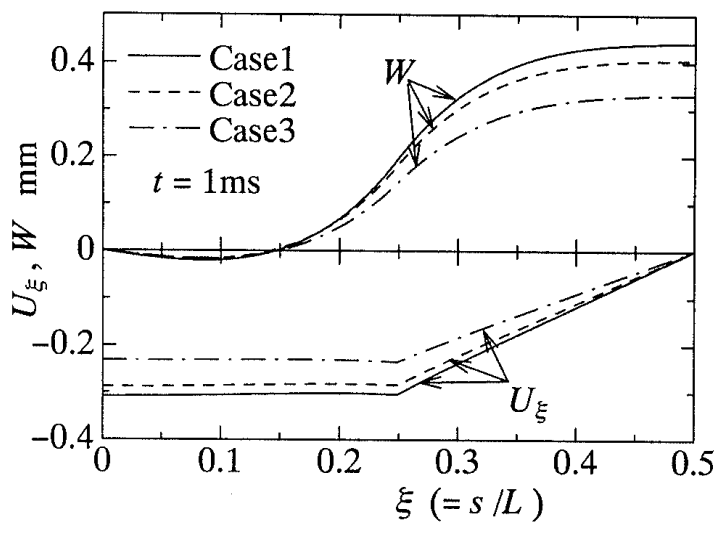

Fig. 13 Meridional distributions of displacements $U_{\xi}$ and $W$

線膨張係数は大きいため, SUS 304 のみの均質殼で は, $\mathrm{ZrO}_{2}$ を含む殼の場合に比べて外表面近傍で温度 が半分以下の低温にもかかわらず，变形量はかなり大 きくなっている.さらに, $\mathrm{ZrO}_{2}$ と SUS 304 の密度の 相違により，密度の小さい $\mathrm{ZrO}_{2}$ を多く含む Case 1 の 殼は, Case 2, 3 の殻に比べて多少早く最大変位に到 達し, その後の変動振幅は小さい。

最後に, 時刻 $t=1 \mathrm{~ms}$ のきの合応力 $N_{\theta}$ と合モー メント $M_{\theta}$ の子午線方向分布を図 14 に示す．図には 示さなかったが，殼体高温部の $N_{\theta}$ および $M_{\theta}$ の時間 的変化は, 各々図 12 の変位 $W$ および図 11 の温度の 時間的変化と類似の忘答を示す。 $N_{\theta}, M_{\theta}$ とも，子午 線方向の温度こう配の極めて大きい点 $\mathrm{B}$ 付近で子午 線方向に急激に変動する。

\section{5. 結言}

本論文では, 衝撃熱負荷を受ける中程度の厚さの傾 斜機能回転対称殼の非定常熱応力・変形問題の解法を 示した，本解法では, 殼の温度分布を求める際に, 殼 厚方向の温度分布を任意の高次曲線で与え, その次数 を変えて解の収束性を調べることにより，精度の高い 温度分布が求められる. 得られた温度分布をもとに, Reissner-Naghdi の殼理論に基づく回転対称殼の基 礎関係式から, 変位, 内力などを求めた。導かれた基 礎式の解值解法には，差分法を適用した。

数値例として，まず無限長円筒殼の内表面に, 流体 加熱が時間に対してステップ状に作用する問題を取り 上げ, 須見らの特性曲線法による数值解析解と比較し た。その結果，殸理論を用いた本解法と特性曲線法を 適用した解法では，変位や内外表面の円周方向応力の 時間的変化においてわずかに違いがあるものの，両結 果は良く一致し, 本解法の妥当性が確認できた。続い て SUS 304 と $\mathrm{ZrO}_{2}$ から成る両端単純可動支持の傾

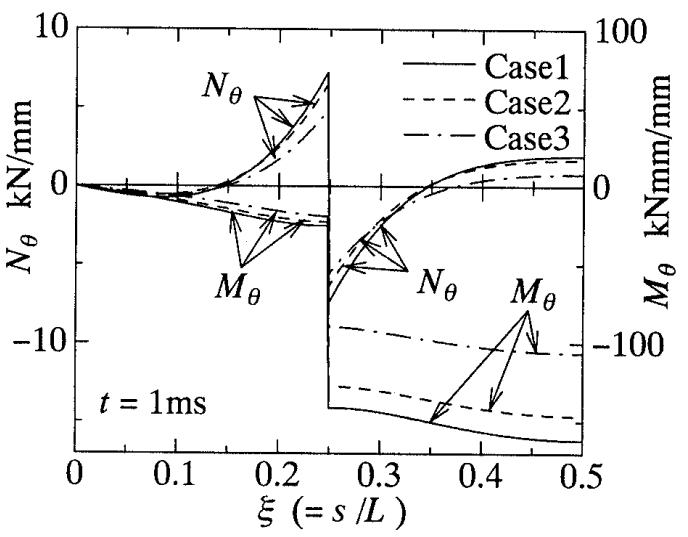

Fig. 14 Meridional distributions of internal forces $N_{\theta}$ and $M_{\theta}$

斜機能円筒殻に，内部発熱による衝撃熱負荷が時間に 対してインパルス状に作用する問題を解析し, SUS 304 のみの均質殼を含む 3 種類の組成傾斜の殼 の応答を調べた。その結果, 3 種類の殼に同一の発熱 量を与えると, $\mathrm{ZrO}_{2}$ を多く含む円筒殼ほど殸体内で より高温となり,また変位, 内力は温度の時間的変化 に類似して変動し，それらの值は $\mathrm{ZrO}_{2}$ を多く含む円 筒款ほど大きくなっている。

近年, 傾斜機能材料から成る平板, 円筒および中空 球などを対象として，材料定数の温度依存性を考慮し た動的熱応力解析がなされ，材料定数の温度依存性の 考虑が不可欠であることが指摘されており ${ }^{(6)}$ ，今後の 課題として本解法にもこれの導入を計る必要がある.

\section{文献}

（1）例えば，野田淔剛・辻知章，機論，57-535，A(1991)，625631．菅野良弘・片岡誠治・田中喜久昭，機諭，59-562，A (1993)，1505-1513. 大多尾義弘 - 谷川義信, 機論, 60-578, A (1994)，2273-2279. 伊藤義康 - 高橋雅士・岡村隆成 - 豊 田政男, 機論, 61-583, A(1995)，614-619. 大多尾義弘・河 村隆介・谷川義信・石丸治, 機論, 64-626, A (1998)，26452652.

（2）須見尚文, 機論, 58-548，A(1992)，574-578.

（3）伊藤禎元 - 須見尚文, 機論, 58-548, A (1992), 579-584.

（4）須見尚文・菅野良弘, 機論, 61-590, A (1995)，2296-2301

（5）須見尚文・門奈博・菅野良弘, 機論, 62-597, A (1996), 1189-1196.

（6）須見尚文, 門奈博, 菅野良弘, 機論, 64-618, A (1998)，333338.

（7）竹園茂男 - 咔克己・小澤義央, 機講論, No. 973-2（19979), $16^{-17}$

（8）稲村栄次郎 - 竹園茂男・垰克己 - 小澤義央, 機論, 63-605, A(1997), 124-131.

(9) Reissner, E., Am. J. Math., 63-1 (1941); 177-184.

(10) Naghdi, P. M., Q. Appl. Math., 14-4 (1957), 369-380.

（11）竹園茂男・沶克己・内堀博雄, 機論, 52-476, A (1986), 997-1005.

（12）竹園茂男 - 咔克己・青木隆・稲村栄次郎, 機論, 59-562, A (1993), 1443-1450

(13) Houbolt, J. C., J. Aeronaut. Sci., 17-9 (1950), 540-550. 